\title{
The Impact of Cervical Conization Size Followed by Cervical Length Changes on Preterm Birth Rates in Asymptomatic Singleton Pregnancies
}

\section{Sergei V. Firichenko}

Moscow Institute of Physics and Technology (National Research University)

\section{Michael Stark}

The New European Surgical Academy (NESA)

Ospan A. Mynbaev ( $\square$ ospanmynbaev@gmail.com )

Moscow Institute of Physics and Technology (National Research University)

\section{Research Article}

Keywords: cervical conization size, asymptomatic singleton pregnancies, cervical length (CL), preterm birth (PTB)

Posted Date: May 6th, 2021

DOI: https://doi.org/10.21203/rs.3.rs-468727/v1

License: (9) This work is licensed under a Creative Commons Attribution 4.0 International License. Read Full License 


\section{Abstract}

The study aimed to explore the impact of the cervical conization size (CCS) followed by cervical length (CL) changes on preterm birth (PTB) rates in asymptomatic singleton pregnancies compared to pregnancy outcomes (POs) in women with an intact cervix, and to estimate the PTB prevention efficiency in patients with a short cervix (vaginal progesterone alone group (PAG) vs. progesterone-pessary group (PPG)). POs in populations with similar age, ethnicity, residency, education, and harmful habits who underwent cervical conization compared to the women with an intact cervix, and sub-populations with the sufficient $C L$ vs. short cervix, and the PTB prevention efficiency of PAG and PPG were retrospectively analyzed. PTB risks depend on the CCS which is the key point, further, during pregnancy, the larger CCS is associated with the short cervix, and higher PTB risks, notably increased among nulliparous women, and the smaller CCS followed by the sufficient CL and lower PTB risks predominantly observed in women with the prior parity. The USCL assessment is the PTB risk predicting tool, and it can be supplemented with the CCS to increase its diagnostic value. There was no substantial impact on the POs associated with the PTB prevention modes, whereas, the CL changes during pregnancy depending on the CCS is more critical in POs.

\section{Introduction}

Preterm birth (PTB) is defined as any birth before 37 weeks of gestation or less than 259 days since the first day of a woman's last menstrual period. ${ }^{1}$ It is estimated that the $15 \mathrm{mln}$ annual PTBs are one of the worldwide healthcare concerns due to the high neonatal mortality, about $1 \mathrm{mln}$ deaths, and severe lifelong morbidity amongst survivors with harmful impact on the individual, family, community, and societal levels of their living. ${ }^{1-6}$ Moreover, the necessity of the high costs of medical services and the needed highly trained professionals is a financial burden of healthcare and the social systems in developed countries. ${ }^{1-3,6-8}$ An expected increasing trend of the global PTB prevalence is based on further improvements of healthcare systems worldwide with the establishment of statistics and registration of PTB in many developing and low-income countries. 1,6, 9,10

Traumatized and shortened cervix due to surgical procedures such as cold knife biopsy, conization, and excisions were presented as a mechanical causative factor of the PTB ${ }^{11,12}$, and its predictor. ${ }^{13-15}$ Further, transvaginal ultrasound cervical length (USCL) measurements were recommended by many professional societies to predict the PTB risks. ${ }^{12,16}$ Historically electrosurgical treatments of cervical pathologies were suggested as a risk factor of PTB ${ }^{17-23}$, although other studies showed an absence of their impact on pregnancy outcome(POs) ${ }^{24-29}$, with conflicting opinions of experts ${ }^{11,12,30}$, because of the complexity of the PTB causative mechanisms. ${ }^{31,32}$

Vaginal progesterone was recommended as noninvasive PTB prevention for asymptomatic women with a short cervix in the special clinical guideline from the Society for Maternal-Fetal Medicine Publications Committee ${ }^{33}$, whereas the use of pessaries has more than 60 -years history since Cross $^{34}$ published 
successful results of the use of 'Bakelite' cervical ring in 13 cases to prevent habitual abortions due to cervical incompetence. This device has been modified and improved by Arabin. ${ }^{35}$ Nowadays both, progesterone and pessaries have been used to prevent PTB in patients with a short cervix, although the efficiency of these treatments is extensively debated in the literature with disputable results for vaginal progesterone ${ }^{36-41}$, cervical pessary $42-48$, and their combination or comparisons. ${ }^{49-52}$

This study was designed to explore the impact of the cervical conization size (CCS) followed by cervical length $(\mathrm{CL})$ changes on the PTB rates of asymptomatic singleton pregnancies compared to POs in women without cervical conization and to estimate the efficiency of vaginal progesterone alone next to its combination with a pessary to prevent PTB in patients with a short cervix.

\section{Materials \& Methods}

Study design \& subjects

This retrospective cohort study was designed in the outpatient unit of the university obstetrics and gynecology hospital of the Moscow State University of Medicine \& Dentistry (MSUMD) named after A.I.Evdokimov. The study protocol was approved by the institutional Ethics Committee of the MSUMD (№ 06-14 / 19.06.2014).

In the university outpatient clinic, more than 3000 electrosurgical cone-shaped (CONE) and loop (LEEP) excisions were performed between 2006-2016 following cervical pathologies, including human papillomavirus-related cervical intraepithelial neoplasia (CIN) grades 2-3 lesions and a combination of CIN grades 1-3 with ectropion or deformation of the cervix after previous births. All diagnostic and treatment methods were carried out following Good clinical practice guidelines, national diagnostic \& treatment standards, and regulations of the Russian Federation healthcare ministry with signed informed consent by the patients. The following inclusion criteria were used to select the medical records of asymptomatic women with POs: 1). Singleton pregnancies with a history of cervical conization before the pregnancy with measurement of the volume of the removed part of the cervix according to our previously described method ${ }^{69} ; 2$ ). Without prior PTB history; 3 ). The transvaginal ultrasound cervical length (USCL) assessments before and after cervical conization and during pregnancy. The USCL measurements during pregnancy were performed in asymptomatic women without miscarriage (PTB) symptoms (uterine contractions, pelvic pressure, a change in vaginal discharge $\left.{ }^{70} ; 4\right)$. An absence of harmful somatic diseases, obesity, and severe pregnancy pathologies.

Following these criteria, 331 medical records were found, including POs of women who had cervical conizations (Fig. 7). Additionally, medical records of singleton POs of asymptomatic women without prior history of cervical conizations (intact cervix) and PTB, as well as with USCL assessments before and during pregnancy were collected. Finally, 621 POs were analyzed in the 1st cohort, grouped: women without cervical conization - the intact cervix group (ICG, $n=290$ ); cervical conization group (CCG, $n=$ 331). Then CCG was divided into two sub-groups depending on CL measured with transvaginal 
ultrasound at the 16-18 gestational weeks with a length of cervix $>25 \mathrm{~mm}$ as the sufficient cervical length group (SCLG, $n=238$ ); with a length of cervix $\leq 25 \mathrm{~mm}$, as the short cervix group (STCG, $n=93$ ).

In the 2nd cohort, 331 women with cervical conizations were grouped depending on cervical length and PTB prevention management modes. Among them, from the 1 st cohort women with sufficient cervical length without PTB prevention (SCLG, $n=238$ ) and other 93 women with short cervix were divided into two sub-groups concerning the PTB prevention modes: progesterone alone group (PAG, $n=70$ ) and progesterone-pessary group (PPG, $n=23$ ). Micronized progesterone vaginal capsules $(200 \mathrm{mg} / \mathrm{daily})$ were prescribed to all pregnant women with an approved diagnosis of the short cervix $(\leq 25 \mathrm{~mm})$ by the USCL assessment, and the treatment continued up to the 34th week of gestation following the current recommendations of the Healthcare Ministry the Russian Federation ("Preterm birth" No. 15-4 / 10 / 2$9480,17.12 .2013)$.

Application of pessary was the choice of the patients. They started to use pessary from the 21-23 weeks of gestation which was inserted after the USCL assessment. Mostly pessary was used between 25-28 weeks and in few cases up to 30 and 31 weeks of gestation. Only one woman started to use pessary from the 15th week of gestation. 20 women used Arabin pessaries (Dr. Arabin GmbH \& Co. KG, Witten, Germany) and 3 patients - Yunona (Simurg, Vitebsk, Belarus) pessaries. There were not any other additional treatments or other activities concerning PTB prevention.

\section{Demographic and obstetric data}

Main demographic parameters, including age, nationality, residency, education status, smoking, prior reproductive (parity) history, and the interval between cervical conization and conception were documented. Newborns in two women were with fatal outcomes. Data concerning the use of antibiotics to prevent intrauterine infection, and other therapeutic agents to improve neonatal outcomes (antenatal corticosteroids and magnesium sulfate) were not included because of the rare cases of these events. Results concerning newborns were also not included in this study.

\section{Methods}

Gynecological checkups of the condition of the cervix included the transvaginal USCL measurements before and after surgical treatment of cervical lesions in non-pregnant women, and during pregnancy.

\section{Electrosurgical excision of the cervical lesions and cervical conization size assessment}

Electrosurgical excision of the cervical lesions was performed utilizing the Electrosurgical unit ESHF-8003-(FOTEK, Ekaterinburg, Russia) using CONUS-shaped and LOOP probes. All surgical procedures were defined as cervical conization. The cervical conization size (CCS) or volume of the excised cervix (tissue specimen) was measured according to our previously described technique. ${ }^{69}$ The measurement system included a syringe containing water $10 \mathrm{ml}$ (Fig. 8, A-D). The tissue specimen is immediately inserted into 
the syringe, which sinks into the water while the level of the wáter is rising; so, the exact volume of the specimen defined as the CCS is estimated.

\section{Transvaginal ultrasound cervical length measurement of non-pregnant women and during pregnancy}

The CL of all patients was evaluated before and one month after cervical conization. The intravaginal probe using ultrasound equipment Siemens Sonoline G 60 (Siemens Healthcare GmbH, Erlangen, Germany) with 6.5 MHz in two-dimensional modes. All measurements were performed during the follicular phase of the menstrual cycle and were repeated three times, where the average values. USCL was performed during the 16-18 weeks of pregnancy. The procedure was done following the technique described by lams et $\mathrm{al}^{13}$, according to their recommendations ${ }^{12,16}$, and the measurements were repeated three times. Then, the average value was recorded. The CL of $>25 \mathrm{~mm}$ was considered a sufficient $\mathrm{CL}$, whereas a CL of $\leq 25 \mathrm{~mm}$ was defined as a short cervix.

\section{The final endpoints}

The final endpoints of the study were the childbirth mode (Cesarean section or vaginal delivery), the rate of the amniotic membrane rupture, and the delivery time from registered active labor period with regular contractions more frequent than every 5 minutes and dilated cervix $3 \mathrm{~cm}$ or more ${ }^{71}$, the duration (length) of pregnancy in weeks, and finally, the rate of spontaneous preterm birth (<37 weeks of gestation).

\section{Statistical analysis}

All medical records were retrieved from the database of the outpatient unit were depersonalized and collected in excel tables for further statistical analysis performed using the program (Graph Pad Prism. 8.0.2). The distribution normality of variables was achieved by using D'Agostino \& Pearson test and assembling QQ plots. Appropriate statistical tests were chosen accordingly to the type of the distributions of the variables. Comparative analysis of groups without repeated variables was performed using an ordinary one-way analysis of variance (ANOVA) with Tukey's multiple comparisons test for variables passed normality tests or nonparametric Kruskal - Wallis and Dunn's multiple comparisons, and MannWhitney tests with alpha $=0.05$ were used when variables did not pass normality tests. Results with repeated measurements were analyzed using two-way ANOVA with Tukey's multiple comparisons test with alpha $=0.05$. The relative risk $(\mathrm{RR})$ and odds ratios $(\mathrm{OR})$ were calculated using two-sided Fisher's exact test with confidential intervals computed with Koopman asymptotic score for RR and Baptista-Pike method for OR, as well as sensitivity and specificity, analyzed with Wilson/Brown method.

Comparisons of the pregnancy prolongation curves between 26-42 weeks of gestation (survival curve) and the childbirth duration were performed using Log-rank (Mantel-Cox), Log-rank for trend, and GehanBreslow-Wilcoxon tests with assembling of the survival curve plots. Results were described and presented as the mean values and proportions (percentages, \%) with standard deviation (SD) or 95\% confidential intervals $(\mathrm{Cl})$, and also as box \& whiskers, or violin plot, and two-sided $\mathrm{P}$-value $<0.05$ was considered as significant. 


\section{Results}

\section{Demographic factors}

Cervical conization procedures followed by pregnancies happened mostly among asymptomatic women in their late twenties (total mean age $28.25 \pm 5.3$ with $95 \% \mathrm{Cl}$ (27.83 to 28.67), Supplementary Table 1). Most of the women were Moscow inhabitants $91.03 \%$ (87.73-94.34) with Slavic $85.51 \%$ (82.73 to 88.28 ); and other $14.49 \%$ (11.72 to 17.27$)$ ethnic groups and achieved education levels: higher $31.4 \%(27.74$ to 35.07); professional $37.84 \%$ (34.02 to 41.67 ); secondary $30.76 \%$ (27.12 to 34.4 ), among them $9.13 \%$ (8.91 to 9.35) were smokers (Supplementary Tables 2-8). Comparisons of all these factors were not significantly different between the groups $(P=N S)$ demonstrating similar demographic composition of the population in groups.

\section{Obstetric factors and pregnancy outcomes}

A significantly higher proportion of the nulliparous population $(p<0.0001)$ was observed in ICG $(65.17 \%$ with $95 \% \mathrm{Cl} 59.66$ to 70.69$)$ than that of $\operatorname{CCG}(48.64 \%$ with $95 \% \mathrm{Cl} 43.23$ to 54.05$)$ supporting the physicians' decisions to avoid performing cervical conizations in nulliparous women (Fig. 1, A). The proportion of the nulliparous population in SCLG (43.28\% with 95\% Cl 36.94 to 49.62$)$ was significantly lower in comparison to similar proportions of all short cervix groups STCG $(P=0.0277)$, PAG $(P=0.0095)$, and PPG $(P=0.0500)$ showing that nulliparous women experienced cervical conization susceptible to shortening of the cervix during pregnancy. The contrary significantly higher proportion of woman who previously has given birth defined as the birth-given women (BGW) was observed among the population in CCG compared to that of women in ICG $(P<0.0019)$ (Fig. 1, B). There was the significantly highest number of GBW observed in SCLG in comparison to groups: ICG $(p<0.0001)$; STCG $(P<0.0004)$; PAG $(P<$ 0.0095).; PPG $(P<0.0017)$ achieved using Mann Whitney tests with Alpha $=0.05$.

In total, the intervals between cervical conization and conception lasted $12.85 \pm 5.32$ months with $95 \% \mathrm{Cl}$ (12.27 to 13.42) among all women with cervical conizations (Supplementary Table 9). Significant differences in the intervals were observed only between SCLG $12.28 \pm 4.61$ (11.69 to 12.87) and PPG $14.96 \pm 5.71(12,49$ to 17.43$)(P=0.0222)$.

The Cesarean section was done in $19 \%$ (95\% $\mathrm{Cl} 15.91$ to $22.1 \%$ ) of cases, whereas $80.19 \%$ (77.05 to $83.34 \%$ ) of women delivered by the natural approach (Supplementary Tables 10,11). Spontaneous ruptures of membranes were observed in $10.69 \%$ (9.33 to 9.87 ) cases in ICG, $7.84 \%$ (7.59 to 8.09) in CCG, $7.84 \%$ (7.5 to 8.16) in SCLG, 7.84\% (7.46 to 8.23) in STCG, 7.7\% (7.31 to 8.2) in PAG, 8.2\% (7.32 to 9.08 in PPG, and $8.96 \%$ (8.75 to 9.18) in total (Supplementary Table 12). The birth lasted 9.6 hours (9.33 to 9.87 ) in ICG, 7.84 hours (7.59 to 8.09) in CCG, 7.84 hours (95\% Cl 7.5 to 8.16) in SCLG, 7.84 hours (7.46 to 8.23) in STCG, 7.7 hours (7.31 to 8.2) in PAG, 8.2 hours (7.32 to 9.08) in PPG (Fig. 1, C). The rates of the Cesarean section and vaginal births, as well as the spontaneous ruptured membranes, were similar among all these comparisons, however, highly significant differences observed in cases of the prolonged deliveries among compared groups, ICG vs. CCG, SCLG, STCG, and PAG, showing the decreased delivery 
time intervals in women with cervical conization independently of CL changes confirmed by the survival curve with log-rank for trend tests $(P<0.0001)$.

\section{The physical volume of cervical conization size (removed cervical tissue volume)}

The mean cervical conization size (CCS) with standard deviations and $95 \%$ confidential intervals (CI) were analyzed among all women with cervical conizations (Fig. 2): CCG $2.36 \pm 0.88$ (95\% Cl 2.27 to 2.46); SCLG $2.16 \pm 0.80$ (95\% Cl 2.06 to 2.26); STCG $2.88 \pm 0.87$ (95\% Cl 2.7 to 3.1 ); PAG $2.73 \pm 0.87$ (5\% $\mathrm{Cl} 2.52$ to 2.93$), P P G 3.33 \pm 0.72$ (95\% $\mathrm{Cl} 3.01$ to 3.64$)$. The significantly smallest CCS was observed in SCLG than that of all other groups: CCG $(P<0.0162), S T C G, P A G$, and PPG $(P<0.0001)$. In turn, the CCS was larger in PPG than that of PAG $(P<0.0139)$ and all other groups $(P<0.0001)$.

\section{The 1st cohort comparisons}

POs of the population with the intact cervix group (ICG, $n=290$ ) in comparison to those of the population with cervical conization group (CCG, $n=331$ ), including two subsets of the CCG: sufficient cervical length group (SCLG, $n=238$ ) and short cervix group (STCG, $n=93)$, were analyzed.

Preterm birth rates between women with vs. without cervical conization, and short vs. sufficient cervical length

The pregnancy lasted in ICG $38.91 \pm 1.31$ with (95\% Cl: 38.76 to 39.07$)$; CCG $39.09 \pm 1.82$ (38.89 to 39.29); SCLG $39.37 \pm 1.27$ (39.2 to 39.53); STCG $38.39 \pm 2.64$ (37.84 to 38.93) weeks (Fig. 3, A). The proportion of the remaining pregnant women between 32-37 weeks of gestation among all cervical conization groups was significantly lower compared to the intact cervix group in the survival curve and confirmed by log-rank for trend tests $(P<0.0001)$.

The PTB rate in SCLG was the lowest $5.88 \%$ with $95 \% \mathrm{Cl}, 2.87$ to $8.89 \%$ among the 1 st cohort (Fig. 3, B), whereas in STCG it was increased up to $23.66 \%$ with $95 \% \mathrm{Cl}, 14.86$ to $32.46 \%$ with significant differences by the Mann-Whitney test $(P<0.0001)$. The PTB rate among women with ICG was significantly lower than that of only in STCG $(P<0.0001)$ and relatively equal to those of other both conization groups: $C C G(P=$ 0.1179); SCLG ( $P=0.5331)$. The PTB rate in STCG was significantly higher than that in CCG and SCLG ( $P$ $<0.0001)$. Among women with STCG, there was significantly increased PTB relative risk $(P<0.0001)$ twofold (RR 1.95; 95\% Cl, 1.37 to 3.08), and the odds ratio raised five folds (OR 4.96; 95\% Cl, 2.41 to 10.4) by two-sided Fisher's exact test. Additionally, the PTB rates were analyzed depending on NP or BGW among these groups (Supplementary Table 13) and there were no significant differences in the internal comparisons in all groups (NP vs. BGW, $P=N S$ ), although among NP observed significant differences observed between groups: ICG vs. STCG $(P=0.0002)$, COG and STCG $(P=0.0011)$; SCLG vs. STCG $(P=$ 0.0011).

Ultrasound cervical length changes during pregnancy of women with vs. without cervical conization, and short vs. sufficient cervical length 
There was a comparable ultrasound cervical length (USCL) before conization (1 vs. 1) among all the studied groups (Fig. 4). During pregnancy (1 vs. 2) the USCL was significantly changed in three groups, ICG, CCG, and STCG $(P<0.0001)$, whereas in SCLG remained without changing. Significantly changes of the USCL during pregnancy ( 2 vs. 2$)$ were found between all four groups $(P<0.0001)$ with the highest degree in women of ICG and the lowest in STCG, as well as the USCL in SCLG, was higher than that of STCG $(P<0.0001)$.

\section{The 2nd cohort comparisons}

The efficiency of the PTB prevention modes was studied by dividing the STCG population into two groups: progesterone alone group (PAG, $n=70)$ and progesterone-pessary group (PPG, $n=23)$ and comparing their outcomes with those of the SCLG.

An impact of preterm birth modes (progesterone alone vs. progesterone-pessary) on the pregnancy duration and preterm birth rates

The pregnancy lasted $38.6 \pm 2.42$ (95\% Cl: 38.02 to 39.18$)$ and $37.74 \pm 3.19$ (95\% Cl: 36.36 to 39.12$)$ weeks respectively in PAG and PPG (Fig. 5, A). The proportion of the remaining pregnant women between 32-38 weeks of gestation among the population with short cervix regardless of the PTB prevention modes was significantly lower compared to that of women with sufficient cervical length in the survival curve and confirmed by the Gehan-Breslow-Wilcoxon test $(P<0.0018)$. Notably, that the curve of the progesterone-pessary group in the survival-curve plot was remaining in the lower position in all observation periods than the curve of the progesterone alone group.

The PTB was registered in 14,15 , and 7 cases (Fig. 5, B), respectively in SCLG (5,88\%), PAG $(21,43 \%$ ) and PPG $(30,43 \%)$ with significant differences $(P<0.0001$ approximate) by the nonparametric Kruskal-Wallis test (Lower 95\% Cl: 28.71; 11.57; 10.09, Upper 95\% Cl: 8.89; 31.28; 50.78). Dunn's multiple comparisons tests showed significant differences between SCLG vs. both PAG and PPG $(P<0.0001)$. Regardless of the lower PTB rate among women in PAG in comparison with that of PPG, there were no significant differences between these two treatment groups $(P=N S)$, although there is a tendency of the lower survival curve between 34-37 gestation weeks and the higher PTB rates among women in PPG than PAG.

Further, comparisons of PTB rates between NP and BGW did not show significant differences $(P=N S)$, although an increased tendency of the PTB rate among NP than that of BGW was remaining in all 3 groups (Supplementary Table 14). There were significantly lower PTB rates among NP in SLCG compared to both groups with a short cervix: SCLG vs. PAG $(P<0.0062)$ and SCLG vs. PPG $(P<0.0118)$, analogously the PTB rates among GBW in SCLG had a lowering tendency than in both short cervix groups: $P A G(P<0.0635)$ and $P P G(P<0.0649)$.

\section{Ultrasound cervical length changes during pregnancy depending on preterm birth modes (progesterone alone vs.}




\section{progesterone-pessary)}

The USCL parameters before ( 1 vs. 1 ) and after (2 vs. 2) conization among nonpregnant women were similar between all groups of the 2 nd cohort (Fig. 6). Electrosurgical procedures significantly reduced the CL (1 vs. 2) among non-pregnant women in SLCG and PAG $(P<0.0001)$ and PPG $(P<0.001)$. Further, the $\mathrm{CL}$ during pregnancy was significantly longer than that of before pregnancy (2 vs. 3$)$ in SCLG (P< $0.0001)$, whereas in the other two groups the $C L$ substantially shortened, in PAG $(P<0.0001)$ and PPG $(P$ $<0.01)$.

\section{Relative risks and odds ratios}

Significantly increased risk ratios, such as relative risk (RR) and odds ratio (OR) of PTB (Table 1) were found among women with a short cervix (STCG) in comparison to women with sufficient cervical length group (SCLG, $p=0.0001$ ) as well as to those of both PTB prevention modalities (PAG, $p=0.0003$ and PPG, $p=0.0005)$. These PTB risk ratios were also higher in STCG compared to ICG $(p=0.0015)$.

\section{Discussion}

POs of asymptomatic women with similar age, ethnicity, residency, educational background, and harmful habits of populations in the intact cervix group (ICG) vs. cervical conization group (CCG) with its subsets after the adjustment for the USCL (SCLG and STCG), and depending on PTB prevention modes (PAG vs PPG) were retrospectively analyzed. Medical records of women with somatic diseases, obesity, and severe pregnancy pathologies were excluded to limit comorbidity factors of the PTB and focus on the impact of the CCS and USCL changes on POs.

Cervical conizations followed by pregnancies were performed mostly among asymptomatic women in their late twenties which is the age of the population with the peak incidence of severe dysplasia. ${ }^{53}$ There was a significantly higher nulliparous proportion among women who underwent cervical conization in comparison to that of women without cervical conization $(p<0.0001)$, supporting the physicians' decisions to avoid cervical conizations in nulliparous women.

The Cesarean section and vaginal birth rates, as well as rupture of the amniotic membranes, were similar between compared populations. Our findings contradicted the literature data showing the increased amniotic membrane ruptures among women with cervical conizations than without ${ }^{54-55}$ and an association of the amniotic membrane ruptures with the impending preterm birth. ${ }^{56}$ The delivery prolongation was significantly decreased among women with cervical conization independently of their $C L(P<0.0001)$ compared to that of the population with the intact cervix, which contradicts the data showing the prolonged duration of delivery time in women with cervical conizations than without. ${ }^{18}$

Our comparisons of the PTB rates and pregnancy duration in women without and with cervical conization in the 1st cohort, when the USCL was not adjusted, were similar to the literature data showing no difference between these populations ${ }^{24,26,29}$ Besides, the PTB rates of women with sufficient CL (> 25 
$\mathrm{mm}$ ) were also similar to those of women without cervical conization, whereas the PTB rate significantly increased in women with a short cervix $(\leq 25)$ in comparison with women without cervical conization, cervical conization in total and sufficient $C L(P<0.001)$. Subsequently, we confirm that the results of studies demonstrating controversial impacts of cervical electrosurgical procedures on the PTB rates ${ }^{11,12}$ in comparison to POs in population or internal controls were dependent on the volume of the $\mathrm{CCS}^{20,56-59}$ and the USCL adjustment. ${ }^{12,13,60}$

The proportion remaining pregnant in the survival curve was significantly lower among women with a short cervix between 32-37 weeks of gestation than in other groups with and without cervical conizations by the Gehan-Breslow-Wilcoxon test $(P<0.0001)$. The survival curve demonstrating the pregnancy duration among women with the short cervix in this study was similar to findings of lams et al ${ }^{13}$ who compared two groups adjusted for USCL $\leq 25 \mathrm{vs}>25 \mathrm{~mm}$. We found similar findings with literature when the increased PTB rates in women with short cervix after cervical conization were remaining with adjusting for maternal age, parity, and smoking ${ }^{61}$, and prior PTB history. ${ }^{62}$ These results showed that the $\mathrm{CL}$ is the cornerstone in the POs after cervical electrosurgical procedures, therefore changes of USCL before and during pregnancy were thoroughly analyzed. The USCL values before pregnancy were similar in all groups, whereas during pregnancy this parameter significantly changed between all comparisons adjusted without and with cervical conization, as well as sufficient and short cervix $(P<0.0001)$. In turn, the USCL during pregnancy was remained non changed only among women with sufficient $\mathrm{CL}$, whereas in women without cervical conization become significantly longer, and in contrast among women with cervical conization it was shorter, and in women, with a short cervix, this parameter extremely shortened $(P<0.0001)$. In our work, we describe for the first time findings of the USCL changes, monitored before and after conization in non-pregnant women and during pregnancy supplemented with the simple method of the CCS assessment, in addition, the short cervix after cervical conization was observed mostly among the nulliparous population, whereas the sufficient $\mathrm{CL}$ in women with the prior parity.

The 2nd cohort comparisons of the PTB prevention modes showed significantly increased PTB rates among women with a short cervix in both groups compared to that of the SCLG $(P<0.0001)$. Analogously pregnancy duration (the proportion remaining pregnant in the survival curve) was significantly shortened among women with a short cervix in PPG compared to that in SCLG $(P<0.0001)$. Our results of the PTB rates and the pregnancy duration among women with short cervix received vaginal progesterone alone were similar with findings ${ }^{39,40}$ and contradicted $37,38,41$, analogously combined progesterone and pessary application outcomes were in agreement ${ }^{49,52}$ and contradicted ${ }^{36,51,63}$ as well as pessary alone in accord $^{45,47,48}$ and contradicted ${ }^{35,42,44}$ with findings of publications using analogous PTB prevention modes. Our observation concerning the efficient similarity of both PTB prevention modes in accord with the literature. ${ }^{49,64}$

The USCL values before and after conization were similar between all groups, although electrosurgical procedures substantially reduced the USCL among nonpregnant women. Interestingly, the USCL during 
pregnancy becomes significantly longer in women with sufficient $C L(P<0.0001)$, whereas in women with short cervix this parameter substantially shortened, in both PTB prevention groups, PAG $(P<0.0001)$ and PPG $(P<0.01)$. Analogously, during pregnancy in both PTB prevention groups the USCL was significantly reduced when compared to that of women in the SCLG $(P<0.0001)$. The biggest CCS was in women with the short cervix treated with progesterone-pessary and the smallest in women with sufficient $C L(P<$ $0.0001)$, subsequently, short CL was associated with the volume of removed samples. These findings in accordance with analogous observations when the size (depth) of removed cervical tissue was taken into account to predict the PTB rates. ${ }^{21,22,57-59}$

Generally, significantly higher PTB rates were observed among women with short cervix groups (STCG, PAG, and PPG) in comparison to those of women without (ICG, $p=0.0001 ; 0.0073 ; 0.0068$ ), and with (CCG, $p=0.0055 ; 0.0959 ; 0.0381$ ) cervical conizations and sufficient cervical length (SCLG, $p=0.0001$; $0.0029 ; 0.0036)$ (Table 2).

Analogously substantially increased risk ratios, such as relative risk and odds ratio of the PTB rates were found among women with a short cervix in comparison to women with sufficient CL as well as to those of both PTB prevention modalities. Both PTB risk ratios were also notably higher in women with short cervix compared to the intact cervix. The $\mathrm{CL}$ depending on the CCS is more critical in POs than the PTB prevention modes in our observations.

It seems that a combination of several factors such as the larger CCS and the shortened USCL at the 1618 weeks of gestation depending on prior history of parity (nulliparous or women who given birth) plays a crucial role in PTB rate in asymptomatic women with singleton pregnancies. Such importance of the CCS in the PTB rates might be related to the high concentrations of neuropeptides, neurotransmitters, oxytocin, and other physiologically active substances in the cervical tissue and lower uterine segment than those of tissues in the upper part of the uterus. ${ }^{65,66}$ The cervix plays an important role during pregnancy and delivery through modification together with the part of the uterine body forming the lower uterine segment. ${ }^{67,68}$ Subsequently, we suggest that excessively cervical conization might lead to tissue insufficiency and impair the structure and function of the cervix.

\section{Strengths}

Singleton POs of similar populations in age, national compositions, residency, background education levels, and possessed bad habits (smoking) of asymptomatic women were retrospectively analyzed. All cervical electrosurgical procedures before pregnancy with measurement of the CCS and most USCL assessments were performed by trained professionals using the same equipment and instrumentation. Then the statistical analysis of all results was performed by the independent researcher. Medical records of women with somatic diseases, obesity, and severe pregnancy pathologies were excluded to limit comorbidity factors of the PTB and focus on the impact of conization size and cervical length changes on POs. Two-step statistics (1st and 2nd cohorts) enable us to demonstrate a significant value of the ultrasound cervical length measurements before and after cervical conization and during pregnancy as 
well as estimate efficiency of the PTB prevention modes, i.e., vaginal progesterone alone and its combination with pessary in women with short cervix adjusting the size of removed tissue, and the USCL changes before and during pregnancy. Observations of the USCL changes monitored before and after conization in non-pregnant women and during pregnancy with the simple method of physical volume (size) assessment of the removed part of the cervix, as well as findings with the highest proportion of the nulliparous women with a short cervix and contrary highest number of women who previously given birth with sufficient cervical length were described for the first time. These results added knowledge to the understanding of controversial PTB rates of the general population of women after cervical conization in comparison with control women without cervical conization before pregnancy and depending on the CCS and CL changes, as well as different PTB prevention modes. We suggest that the diagnostic and predicting value of the USCL assessment during pregnancy will be increased if take into account CCS.

\section{Limitations}

Our study has limitations due to the retrospective study design: a small number of patients in the group with combined application of progesterone and pessary, as well as using two models of pessaries, which could lead to decrease statistical power of our analysis. The comparison bodies of the PTB prevention modes were populations with an intact cervix, and with the cervical conization in total, and with sufficient $\mathrm{CL}$ adjusted during pregnancy, however, we could not provide the group with analogous short cervix without treatment, placebo, or used the only pessary because of an ethical reason and necessity to follow the PTB management guidelines by the Healthcare Ministry of the Russian Federation. Women had delivered in different maternity houses and medical centers in Moscow, but with relatively similar quality of services, although it might be considered as a limitation of our study. The retrospective nature of the study hampered our ability to collect data concerning newborns.

\section{Conclusions}

Our study shed light on the conflicting conclusions concerning the duplicity impact of cervical conization on POs. The PTB risk was demolished in comparisons of populations with cervical conization and intact cervix when the $\mathrm{CL}$ was not taken into account with somewhat provocative misleading results.. The PTB risks depend on the CCS which is the key point, further, during pregnancy, the larger CCS is associated with the short cervix, and higher PTB risks, notably increased among nulliparous women, and the smaller CCS followed by the sufficient CL and lower PTB risks predominantly observed among women with the prior parity. The USCL assessment is the PTB risk predicting tool, and it can be supplemented with the CCS to increase its diagnostic value. There was no substantial impact on the POs associated with the PTB prevention modes, whereas, the $C L$ changes during pregnancy depending on the CCS is more critical in POs.

\section{Declarations}

\section{Acknowledgments}


We thank Mrs. Julia Firichenko for her help with drawing Fig. 8, and Prof. Igor B. Manukhin the head of the Obstetrics \& Gynecology department of the Faculty of Medicine at Moscow State University of Medicine and Dentistry (named after A.I.Evdokimov) for his consultation and substantial help to the successful running of this project.

\section{Consent for publication}

Depersonalized medical records from the outpatient unit of the Obstetric \& Gynecology department of the Faculty of Medicine at Moscow State University of Medicine and Dentistry (named after A.I.Evdokimov) were collected and retrospectively analyzed. Initially, individual personal data by GPR guidelines with signed informed consent was received from all patients, when they experienced diagnostic and therapeutic interventions. Any direct medical interventions were not performed during this retrospective study.

\section{Data Availability Statement}

All relevant data are within the paper, and the authors can make available materials if requested.

\section{Competing interests}

The authors declare that they have no competing interests.

\section{Funding}

No funding sources.

All authors participated in this project on behalf of The International Bureau of Human Body Design, Biomodeling \& Biosensoring.

\section{Author Contributions}

S.V.F. contributed to the conception and hypothesis, carried out all diagnostic and treatment procedures in patients with cervical pathologies with measurements of the CCS, collected all medical records, M.S. reviewed literature, contributed to the conception and hypothesis, revised the draft of the manuscript, O.A.M. project leading researcher, reviewed literature, substantially contributed to the conception, hypothesis building and the study design of the project, statistical analysis, drafting and revision of the manuscript and correspondence. All authors read and approved the final version of the manuscript.

\section{Duplicate publication statement}

In this study, the results of practical work for more than 10 years (2006-2016) were retrospectively analyzed. Therefore some preliminary results were published in the Russian language journals: results for 2007-2010 years with the number of patients $(n=150)^{72} ;(2007-2011, n=316)^{73} ;(2006-2014, n=314) .{ }^{74}$ In these publications, different aspects of this problem were analyzed aimed to establish the relative volume 
of the cervix after conization and its impact on the women's reproductive health, but not the new concept presented in this manuscript and the whole materials collected in this study $(2006-2016$ years, $n=621)$ were not included in any previous publications. We cited the previously published correspondence with the description of the CCS assessement ${ }^{69}$ and we did not use any original figures from previous publications and the principles of the technique were presented in Fig. 8, by the new drawings with the acknowledgments to the painter.

\section{References}

1. World Health Organization,2. Preterm birth. http://www.who.int/en/news-room/factsheets/detail/preterm-birth. 2018. Annual report, 19 February 2018.

2. Liu, L. et al. Global, regional, and national causes of under-5 mortality in 2000-15: an updated systematic analysis with implications for the Sustainable Development Goals. Lancet. 388 (10063), 3027-3035 (2016).

3. Blencowe, H. et al. Estimates of neonatal morbidities and disabilities at regional and global levels for 2010: introduction, methods overview, and relevant findings from the Global Burden of Disease study. Pediatr. Res. 74 (Suppl 1), 4-16 (2013).

4. Vogel, J. P. et al. The global epidemiology of preterm birth. Best. Pract. Res. Clin. Obstet. Gynaecol. 52, 3-12 (2018).

5. Chawanpaiboon, S. et al. Global, regional, and national estimates of levels of preterm birth in 2014: a systematic review and modelling analysis. Lancet Glob. Health. 7, e37-e46 (2019).

6. Walani, S. R. Global burden of preterm birth. Int. J. Gynaecol. Obstet. 150, 31-33 (2020).

7. Di Renzo, G. C. \& Roura L.C. Guidelines for the management of spontaneous preterm labor. J. Perinat. Med. 34, 359-366 (2006).

8. Institute of Medicine (US). Committee on Understanding Premature Birth and Assuring Healthy Outcomes Preterm Birth: Causes, Consequences, and Prevention (National Academies Press (US), Washington (DC), 2007).

9. Vogel, J. P., Oladapo, O. T., Manu, A., Gulmezoglu, A. M. \& Bahl, R. New WHO recommendations to improve the outcomes of preterm birth. Lancet Glob. Health. 3, e589-e590 (2015).

10. Lincetto, O. \& Banerjee, A. World Prematurity Day: improving survival and quality of life for millions of babies born preterm around the world. Am. J. Physiol Lung Cell Mol. Physiol. 319, L871-L874 (2020).

11. Bevis, K. S. \& Biggio, J. R. Cervical conization and the risk of preterm delivery. Am. J. Obstet. Gynecol. 205, 19-27 (2011).

12. Reicher, L., Fouks, Y. \& Yogev, Y. Cervical Assessment for Predicting Preterm Birth-Cervical Length and Beyond.J. Clin. Med.10, (2021).

13. lams, J. D. et al. The length of the cervix and the risk of spontaneous premature delivery. National Institute of Child Health and Human Development Maternal Fetal Medicine Unit Network. N. Engl. J. 
Med. 334, 567-572 (1996).

14. Berghella, V., Pereira, L., Gariepy, A. \& Simonazzi, G. Prior cone biopsy: prediction of preterm birth by cervical ultrasound. Am. J. Obstet Gynecol. 191, 1393-1397 (2004).

15. Souza, R. T. et al. Clinical and epidemiological factors associated with spontaneous preterm birth: a multicentre cohort of low risk nulliparous women. Sci. Rep. 10, 855 (2020).

16. Lim, K., Butt, K. \& Crane, J. M. SOGC Clinical Practice Guideline. Ultrasonographic cervical length assessment in predicting preterm birth in singleton pregnancies. J. Obstet Gynaecol. Can. 33, 486499 (2011).

17. Miller, N. F. \& Todd, O. H. Conization of the cervix. Surg Gynecol Obstet. 67, 265-270 (1938).

18. Jones, J. M., Sweetnam, P. \& Hibbard, B. M. The outcome of pregnancy after cone biopsy of the cervix: a case-control study. Br. J. Obstet. Gynaecol. 86, 913-916 (1979).

19. Larsson, G., Grundsell, H., Gullberg, B. \& Svennerud, S. Outcome of pregnancy after conization. Acta Obstet. Gynecol. Scand. 61, 461-466 (1982).

20. Sadler, L. et al. Treatment for cervical intraepithelial neoplasia and risk of preterm delivery. JAMA. 291, 2100-2106 (2004).

21. Kyrgiou, M. et al. Adverse obstetric outcomes after local treatment for cervical preinvasive and early invasive disease according to cone depth: systematic review and meta-analysis. BMJ. 354, i3633 (2016).

22. Weinmann, S. et al. Pregnancy Outcomes after Treatment for Cervical Cancer Precursor Lesions: An Observational Study. PLoS. One. 12, e0165276 (2017).

23. Wittmaack, A., Dudley, D. \& Boyle, A. Maternal History of Cervical Surgery and Preterm Delivery: A Retrospective Cohort Study. J. Womens Health (Larchmt.). 28, 1538-1542 (2019).

24. Acharya, G. et al. Pregnancy outcome after loop electrosurgical excision procedure for the management of cervical intraepithelial neoplasia. Arch. Gynecol. Obstet. 272, 109-112 (2005).

25. Tarrant, M. J. \& Gordon, H. Pregnancy outcome following large loop excision of the transformation zone. Journal of Obstetrics and Gynaecology. 13, 348-349 (1993).

26. Ferenczy, A., Choukroun, D., Falcone, T. \& Franco, E. The effect of cervical loop electrosurgical excision on subsequent pregnancy outcome: North American experience. Am. J. Obstet. Gynecol. 172, 1246-1250 (1995).

27. McLaren, H. C., Jordan, J. A., Glover, M. \& Attwood, M. E. Pregnancy after cone biopsy of the cervix. J. Obstet. Gynaecol. Br. Commonw. 81, 383-384 (1974).

28. Naleway, A. L. et al. Pregnancy after treatment for cervical cancer precursor lesions in a retrospective matched cohort. PLoS. One. 10, e0117525 (2015).

29. Werner, C. L. et al. Loop electrosurgical excision procedure and risk of preterm birth. Obstet. Gynecol. $115,605-608$ (2010).

30. Sadler, L. \& Saftlas A. Cervical surgery and preterm birth. J. Perinat. Med. 35, 5-9 (2007). 
31. Manuck, T. A. et al. The phenotype of spontaneous preterm birth: application of a clinical phenotyping tool. Am. J. Obstet. Gynecol. 212, 487 (2015).

32. Romero, R. et al. The preterm parturition syndrome. BJOG. 113 Suppl 3, 17-42 (2006).

33. Society for Maternal-Fetal Medicine. Publications Comittee,w.a.o.B.V. Progesterone and preterm birth prevention: translating clinical trials data into clinical practice. Am. J. Obstet. Gynecol. 206, 376-386 (2012).

34. Cross, R. G. Treatment of habitual abortion due to cervical incompetence. Lancet. 274, 127 (1959).

35. Arabin, B., Halbesma, J. R., Vork, F. \& Hubener, M. \& van,E.J. Is treatment with vaginal pessaries an option in patients with a sonographically detected short cervix? J. Perinat. Med. 31, 122-133 (2003).

36. Conde-Agudelo, A. et al. Vaginal progesterone is as effective as cervical cerclage to prevent preterm birth in women with a singleton gestation, previous spontaneous preterm birth, and a short cervix: updated indirect comparison meta-analysis. Am. J. Obstet. Gynecol. 219, 10-25 (2018).

37. Fonseca, E. B., Celik, E., Parra, M., Singh, M. \& Nicolaides, K. H. Progesterone and the risk of preterm birth among women with a short cervix. N. Engl. J. Med. 357, 462-469 (2007).

38. Hassan, S. S. et al. Vaginal progesterone reduces the rate of preterm birth in women with a sonographic short cervix: a multicenter, randomized, double-blind, placebo-controlled trial. Ultrasound Obstet. Gynecol. 38, 18-31 (2011).

39. Norman, J. E. et al. Vaginal progesterone prophylaxis for preterm birth (the OPPTIMUM study): a multicentre, randomised, double-blind trial. Lancet. 387, 2106-2116 (2016).

40. Norman, J. E. et al. Does progesterone prophylaxis to prevent preterm labour improve outcome? A randomised double-blind placebo-controlled trial (OPPTIMUM). Health Technol. Assess. 22, 1-304 (2018).

41. Romero, R. et al. Vaginal progesterone for preventing preterm birth and adverse perinatal outcomes in singleton gestations with a short cervix: a meta-analysis of individual patient data. Am. J. Obstet. Gynecol. 218, 161-180 (2018).

42. Abdel-Aleem, H., Shaaban, O. M. \& Abdel-Aleem M.A. Cervical pessary for preventing preterm birth.Cochrane. Database. Syst. Rev.CD007873 (2013).

43. Acharya, G. et al. Noninvasive cerclage for the management of cervical incompetence: a prospective study. Arch. Gynecol. Obstet. 273, 283-287 (2006).

44. Goya, M. et al. Cervical pessary in pregnant women with a short cervix (PECEP): an open-label randomised controlled trial. Lancet. 379, 1800-1806 (2012).

45. Jin, X. H., Li, D. \& Huang, L. L. Cervical Pessary for Prevention of Preterm Birth: A Meta-Analysis. Sci. Rep. 7, 42560 (2017).

46. Mendoza, C. M., Ribera, I., Maiz, N., Goya, M. \& Carreras, E. Cervical modifications after pessary placement in singleton pregnancies with maternal short cervical length: 2D and 3D ultrasound evaluation. Acta Obstet. Gynecol. Scand. 98, 1442-1449 (2019). 
47. Nicolaides, K. H. et al. A Randomized Trial of a Cervical Pessary to Prevent Preterm Singleton Birth. N. Engl. J. Med. 374, 1044-1052 (2016).

48. Saccone, G. et al. Cervical Pessary for Preventing Preterm Birth in Singleton Pregnancies With Short Cervical Length: A Systematic Review and Meta-analysis. J. Ultrasound Med. 36, 1535-1543 (2017).

49. Cruz-Melguizo, S. et al. Cervical Pessary Compared With Vaginal Progesterone for Preventing Early Preterm Birth: A Randomized Controlled Trial. Obstet. Gynecol. 132, 907-915 (2018).

50. Daskalakis, G. et al. Evaluation of the efficacy of cervical pessary combined with vaginal progesterone in women with a short cervix and additional risk factors for preterm delivery. J. Matern. Fetal Neonatal Med. 34, 1277-1283 (2021).

51. Melcer, Y. et al. Arabin cervical pessary with vaginal progesterone versus vaginal progesterone for preventing preterm delivery. J. Matern. Fetal Neonatal Med. 33, 3439-3444 (2020).

52. Stricker, N., Timmesfeld, N., Kyvernitakis, I., Goerges, J. \& Arabin B. Vaginal progesterone combined with cervical pessary: A chance for pregnancies at risk for preterm birth? Am. J. Obstet. Gynecol. 214, 739 (2016).

53. Coppell, K., Paul, C. \& Cox B. An evaluation of the National Cervical Screening Programme Otago site. N. Z. Med. J. 113, 48-51 (2000).

54. Svare, J. A. et al. The relationship between prior cervical conization, cervical microbial colonization and preterm premature rupture of the membranes. Eur. J. Obstet Gynecol Reprod. Biol. 47, 41-45 (1992).

55. Sjoborg, K. D. et al. Pregnancy outcome after cervical cone excision: a case-control study. Acta Obstet Gynecol Scand. 86, 423-428 (2007).

56. Lee, S. M., Park, K. H., Jung, E. Y., Jang, J. A. \& Yoo, H. N. Frequency and clinical significance of short cervix in patients with preterm premature rupture of membranes. PLOS. One. 12, e0174657 (2017).

57. Blomfield, P. I., Buxton, J., Dunn, J. \& Luesley, D. M. Pregnancy outcome after large loop excision of the cervical transformation zone. Am. J. Obstet. Gynecol. 169, 620-625 (1993).

58. Berretta, R. et al. Risk of preterm delivery associated with prior treatment of cervical precancerous lesion according to the depth of the cone. Dis. Markers. 35, 721-726 (2013).

59. Noehr, B., Jensen, A., Frederiksen, K., Tabor, A. \& Kjaer, S. K. Depth of cervical cone removed by loop electrosurgical excision procedure and subsequent risk of spontaneous preterm delivery. Obstet. Gynecol. 114, 1232-1238 (2009).

60. Kyrgiou, M. et al. Obstetric outcomes after conservative treatment for cervical intraepithelial lesions and early invasive disease. Cochrane. Database. Syst. Rev. 11, CD012847 (2017).

61. Jakobsson, M., Gissler, M., Sainio, S., Paavonen, J. \& Tapper, A. M. Preterm delivery after surgical treatment for cervical intraepithelial neoplasia. Obstet. Gynecol. 109, 309-313 (2007).

62. Jakobsson, M., Gissler, M., Paavonen, J. \& Tapper, A. M. Loop electrosurgical excision procedure and the risk for preterm birth. Obstet. Gynecol. 114, 504-510 (2009). 
63. Fox, N. S. et al. Cervical Pessary and Vaginal Progesterone in Twin Pregnancies With a Short Cervix. Obstet Gynecol. 127, 625-630 (2016).

64. Sieroszewski, P., Jasinski, A., Perenc, M., Banach, R. \& Oszukowski, P. The Arabin pessary for the treatment of threatened mid-trimester miscarriage or premature labour and miscarriage: a case series. J. Matern. Fetal Neonatal Med. 22, 469-472 (2009).

65. Kosmas, I. P. et al. Adrenergic and Cholinergic Uterine Innervation and the Impact on Reproduction in Aged Women. Curr. Pharm. Des. 26, 358-362 (2020).

66. Malvasi, A. et al. The opioid neuropeptides in uterine fibroid pseudocapsules: a putative association with cervical integrity in human reproduction. Gynecol. Endocrinol. 29, 982-988 (2013).

67. Vink, J. \& Myers, K. Cervical alterations in pregnancy. Best. Pract. Res. Clin. Obstet. Gynaecol. 52, 88$102(2018)$.

68. Mynbaev, O. A. \& et al Uterine Morbidity: Cesarean Section Scar Complications in Hysteroscopy. (ed. Tinelli A.,A.P.L.H.S.)421-468(Springer, Cham., 2018).

69. Mynbaev, O. A. \& Firichenko, S. V. The obstetrical prognosis after "coin-shaped" conization in patients with $\mathrm{CIN}$ : concerns concerning an unclear study design and a lack of specimen size estimation. Arch. Gynecol. Obstet. 294, 439-441 (2016).

70. Lewis, D. et al. Uterine contractions in asymptomatic pregnant women with a short cervix on ultrasound. J. Matern. Fetal Neonatal Med. 18, 325-328 (2005).

71. Su, M. et al. Planned Cesarean section decreases the risk of adverse perinatal outcome due to both labour and delivery complications in the Term Breech Trial. BJOG. 111 (10), 1065-1074 (2004).

72. Firichenko, S. V. et al. Electrosurgical cervical excision, and preterm delivery risk.Russian J. of Hum. Reprod. (4),95-99, (2012), [Rus.].

73. Firichenko, S. V. et al. Electrosurgical excision of the uterine cervix and the reproductive function. Prob. of Gyn. Obstet. \& Perinat. 11 (6), 19-25 (2012). [Rus.].

74. Firichenko, S. V. The reproductive function maintaining of women with cervical premalignant conditions. D.Sc. thesis, Moscow State University of Medicine and Dentistry named after A.I.Evdokimov, Moscow, 294 p(2017), [Rus.].

\section{Tables}

Table 1. The preterm birth relative risk (RR) and odds ratio (OR) parameters between groups, including intact cervix group (ICG), cervix conization group (CCG), sufficient cervical length group (SCLG), short cervix group (STCG), progesterone alone group (PAG), and progesterone-pessary group (PPG), achieved using two-sided Fisher's exact test with confidential intervals $(\mathrm{Cl})$ computed using Koopman asymptotic score for RR and Baptista-Pike method for OR. 


\begin{tabular}{|lllllllll|}
\hline \multicolumn{2}{|c}{ Comparisons (versus) } & RR & $95 \% \mathrm{Cl}$ & OR & $95 \% \mathrm{Cl}$ & Likelihood ratio & P values \\
\hline 1 & ICG & CCG & 0.83 & 0.69 to 1.05 & 0.64 & 0.37 to 1.11 & 0.96 & 0.1271 \\
\hline 2 & ICG & SCLG & 1.1 & 0.79 to 1.39 & 1.25 & 0.63 to 2.53 & 1.23 & 0.6000 \\
\hline 3 & ICG & STCG & 0.69 & 0.49 to 0.88 & 0.33 & 0.17 to 0.65 & 0.37 & 0.0015 \\
\hline 4 & SCLG & STCG & 1.95 & 1.37 to 3.08 & 4.96 & 2.41 to 10.4 & 1.23 & 0.0001 \\
\hline 5 & SCLG & PAG & 1.66 & 1.22 to 2.57 & 4.36 & 2.03 to 9.24 & 1.2 & 0.0003 \\
\cline { 3 - 8 } & & PPG & 1.4 & 1.12 to 2.06 & 7.00 & 2.64 to 20.5 & 1.3 & 0.0008 \\
\hline & PAG & PPG & 1.14 & 0.88 to 1.66 & 1.60 & 0.61 to 4.44 & 1.13 & 0.4043 \\
\hline
\end{tabular}

Table 2. $P$ values of the preterm birth rates between groups, including intact cervix group (ICG), cervix conization group (CCG), sufficient cervix length group (SCLG), short cervix group (STCG), progesterone alone group (PAG), and progesterone-pessary group (PPG), achieved using one-way ANOVA with Tukey's multiple comparisons tests.

\begin{tabular}{|llllll|}
\hline \multirow{2}{*}{ Groups } & \multicolumn{5}{l}{ P-values of the preterm birth rates between compared groups } \\
\cline { 2 - 6 } & CCG & SCLG & STCG & PAG & PPG \\
\hline ICG & 0.6836 & 0.9960 & $\mathbf{0 . 0 0 0 1}$ & $\mathbf{0 . 0 0 7 3}$ & $\mathbf{0 . 0 0 6 8}$ \\
\hline CCG & - & 0.3956 & $\mathbf{0 . 0 0 5 5}$ & 0.0959 & $\mathbf{0 . 0 3 8 1}$ \\
\hline SCLG & - & - & $\mathbf{0 . 0 0 0 1}$ & $\mathbf{0 . 0 0 2 9}$ & $\mathbf{0 . 0 0 3 6}$ \\
\hline STCG & - & - & - & 0.9975 & 0.9341 \\
\hline PAG & - & - & - & - & 0.8277 \\
\hline
\end{tabular}

\section{Figures}



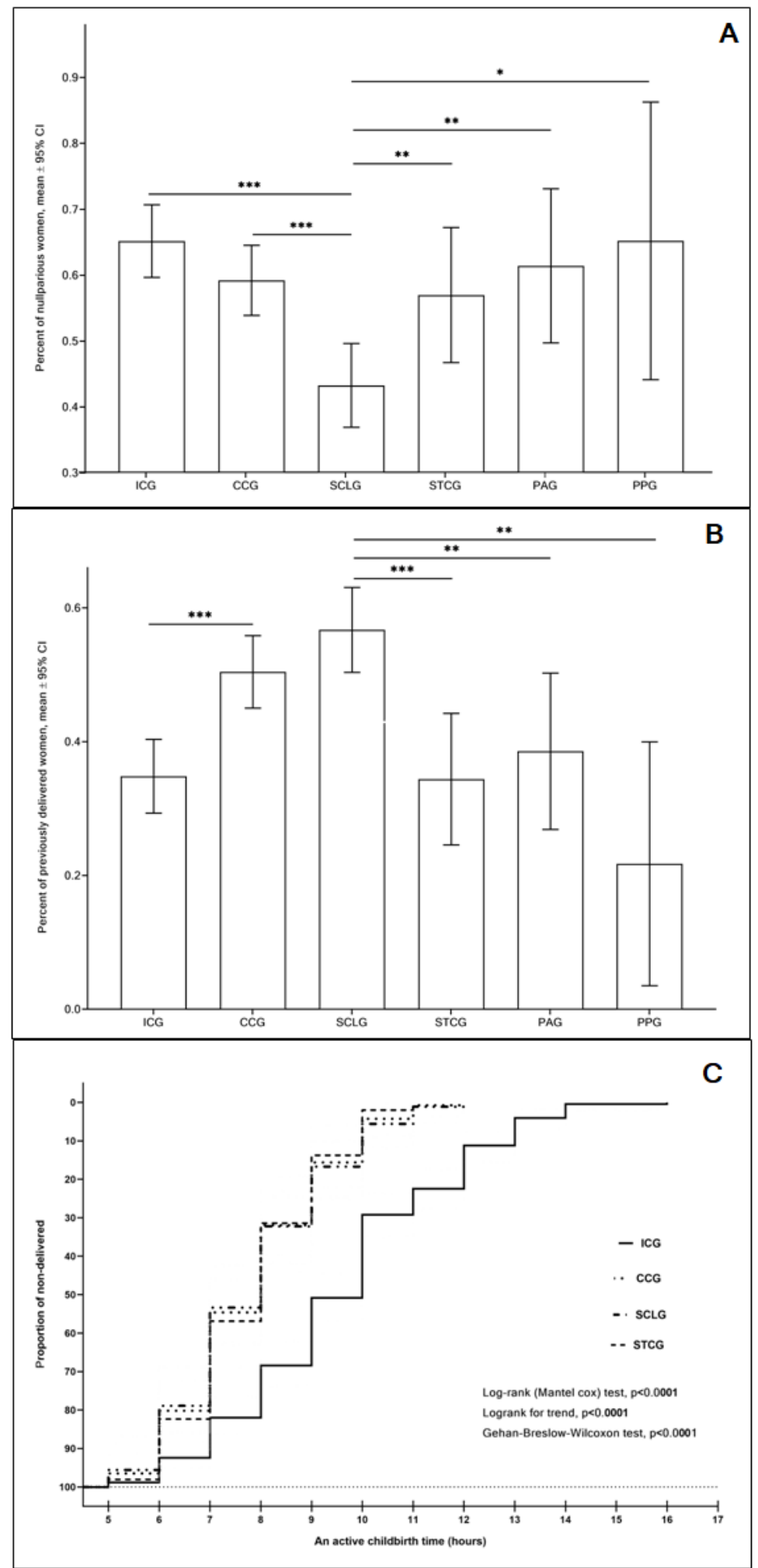

Figure 1

The proportion of nulliparous women (A, unit: \%o) and the proportion remaining non-delivered or delivery time intervals $(B$, unit: proportion remaining non-delivered and hours) among asymptomatic women with singleton pregnancies in the intact cervix group (ICG), cervical conization group (CCG), sufficient cervix length group (SCLG, and short cervix group (STCG), progesterone alone group (PAG), and progesterone- 
pessary group (PPG), P-values achieved using Kruskal-Wallis with Dunn's multiple comparisons, and Mann Whitney tests with Alpha $=0.05$.

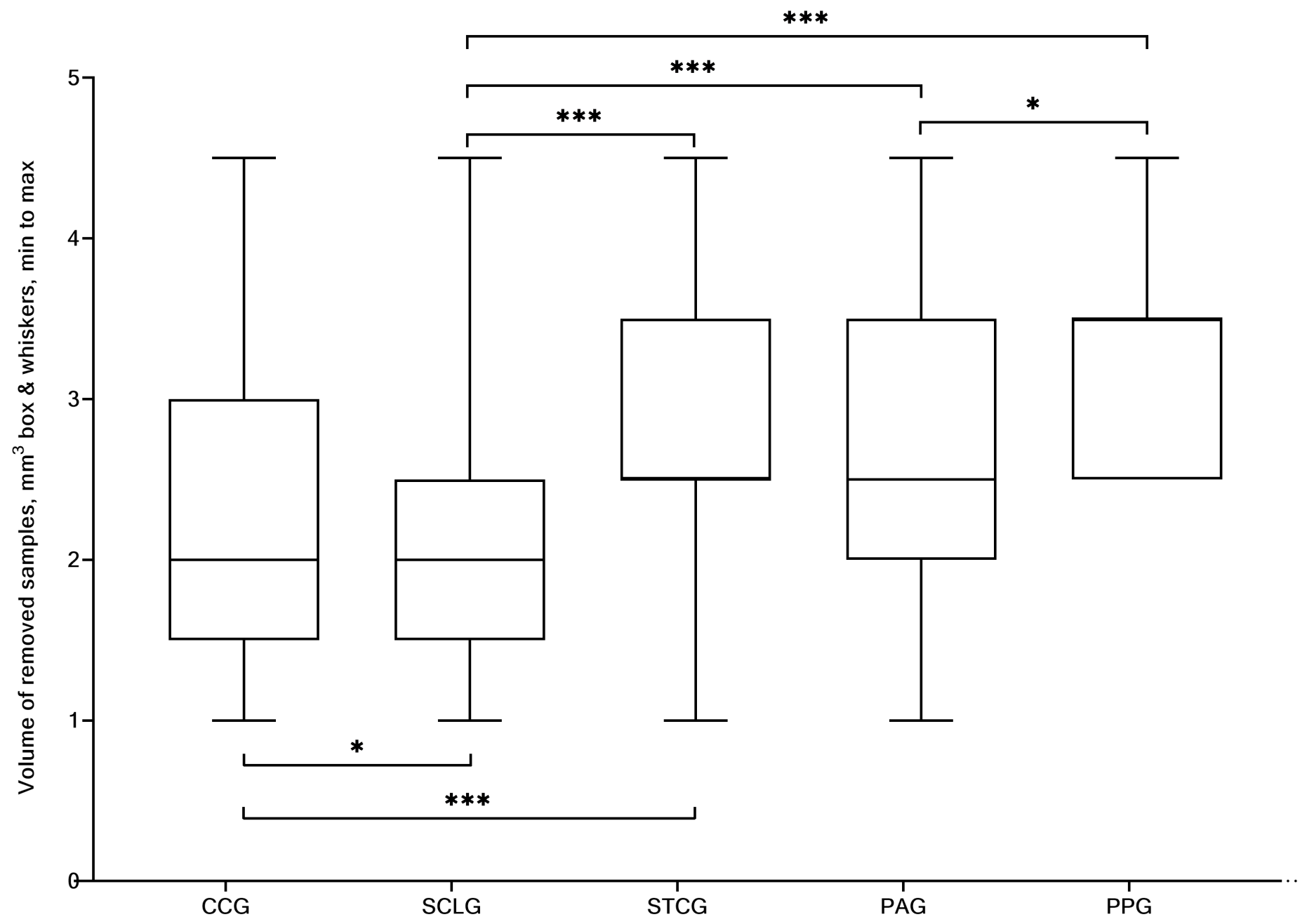

Figure 2

The physical volume of removed samples (unit: $\mathrm{mL} 3$ ) in women with cervix conization group (CCG), sufficient cervix length group (SCLG) without treatment, and patient with a short cervix group (STCG) with its subgroups progesterone alone group (PAG), and progesterone-pessary group (PPG). P-values achieved using one-way ANOVA with Holm-Sidak's multiple comparisons tests with Alpha $=0.05$. 


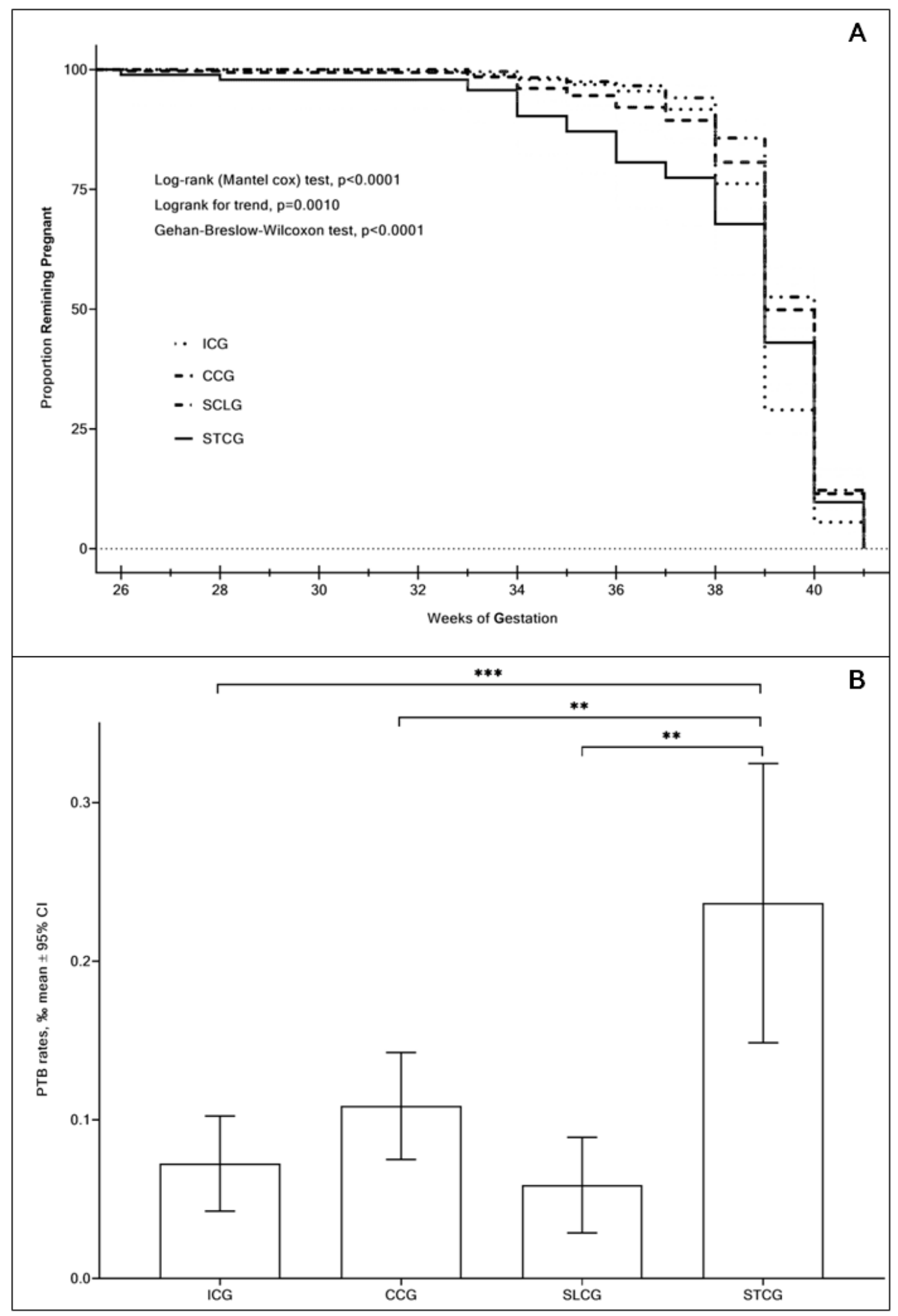

Figure 3

The pregnancy duration curve (the proportion remaining pregnant), (unit: proportion remaining pregnant between 26-42 weeks), and preterm birth (PTB) rates (unit: \%o) among asymptomatic women with singleton pregnancies in groups of the first cohort: intact cervix group (ICG), cervix conization group (CCG), the sufficient cervix length group (SCLG) and short cervix group (STCG). P-values achieved using Kruskal-Wallis with Dunn's multiple comparisons tests with Alpha $=0.05$. 


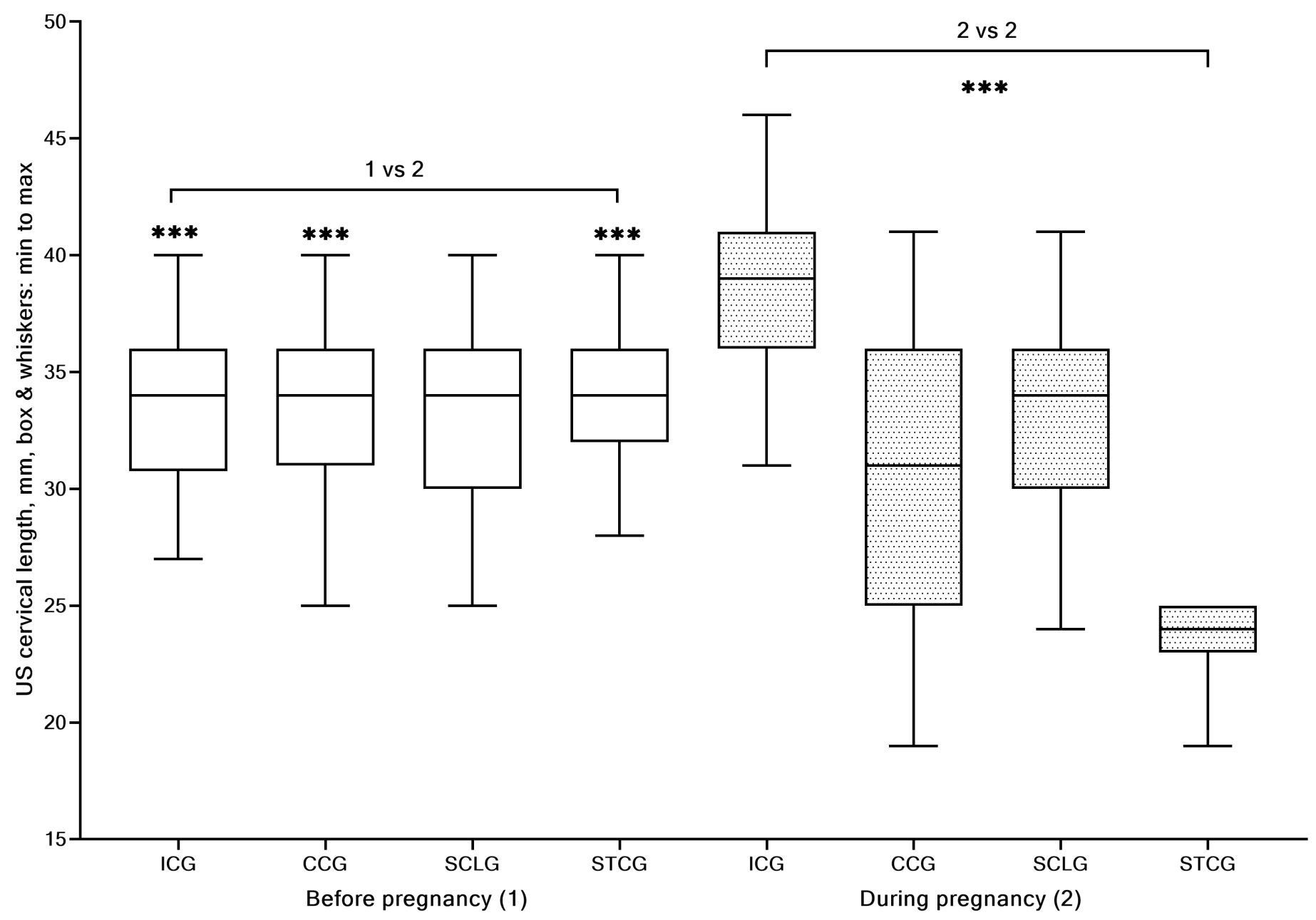

Figure 4

Ultrasound cervical length ( $A$, unit: $\mathrm{mm}$, box \& whiskers, min to max) assessed in non-pregnant women before cervical conization (1) and during pregnancy (2) among asymptomatic women with singleton pregnancies with intact cervix group (ICG), cervical conization group (CCG), sufficient cervix length group (SCLG, and short cervix group (STCG). 


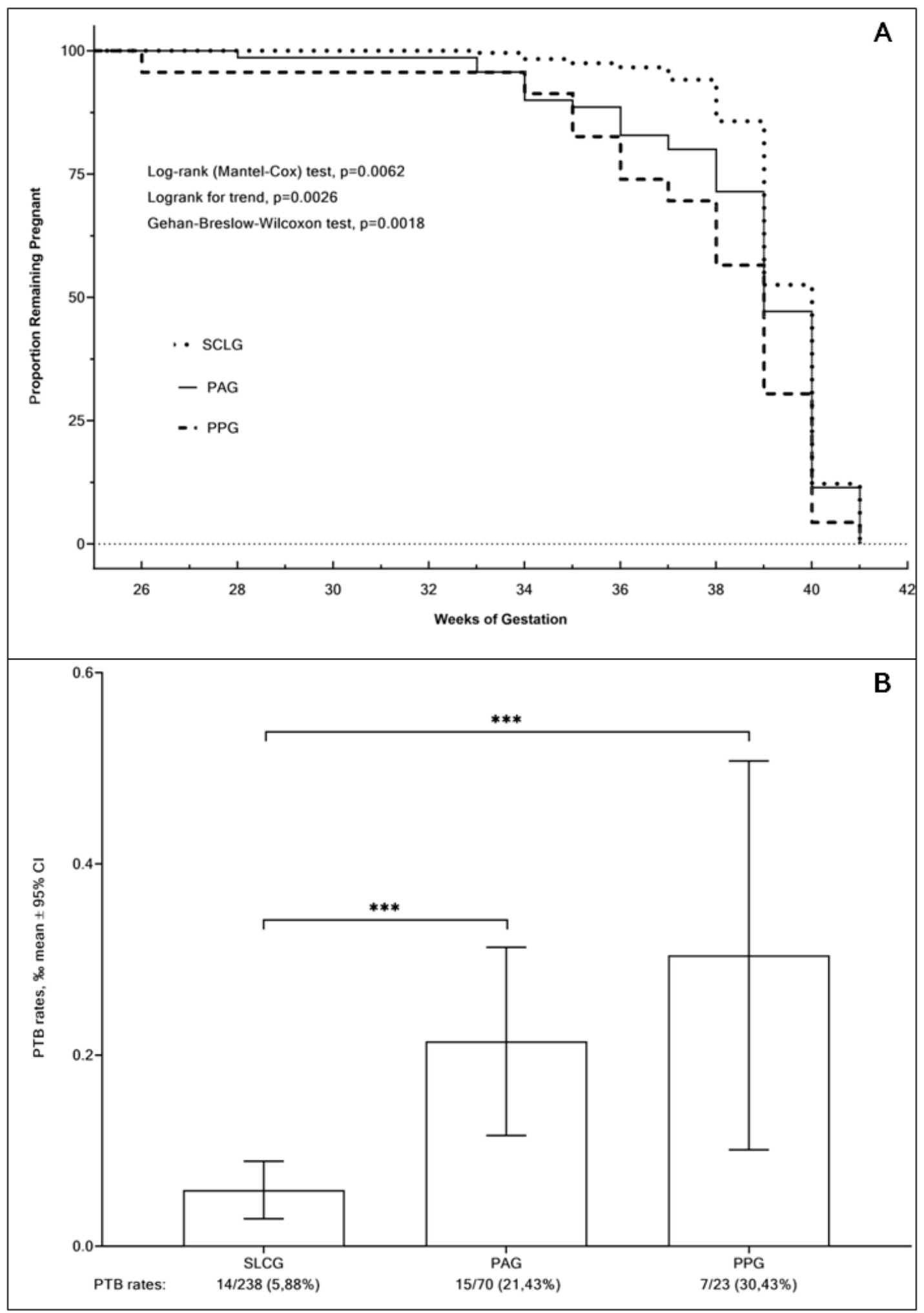

\section{Figure 5}

The pregnancy prolongation curve (the proportion remaining pregnant), (unit: proportion remaining pregnant between 26-42 weeks), and preterm birth rate (unit: \%o) among asymptomatic women with singleton pregnancies with the short cervix in progesterone alone group (PAG), and progesterone-pessary group (PPG), in comparison with those of women with sufficient cervix group length (SCLG) without 
treatment group. P-values achieved using nonparametric Kruskal-Wallis and Dunn's multiple comparisons tests with Alpha $=0.05$.

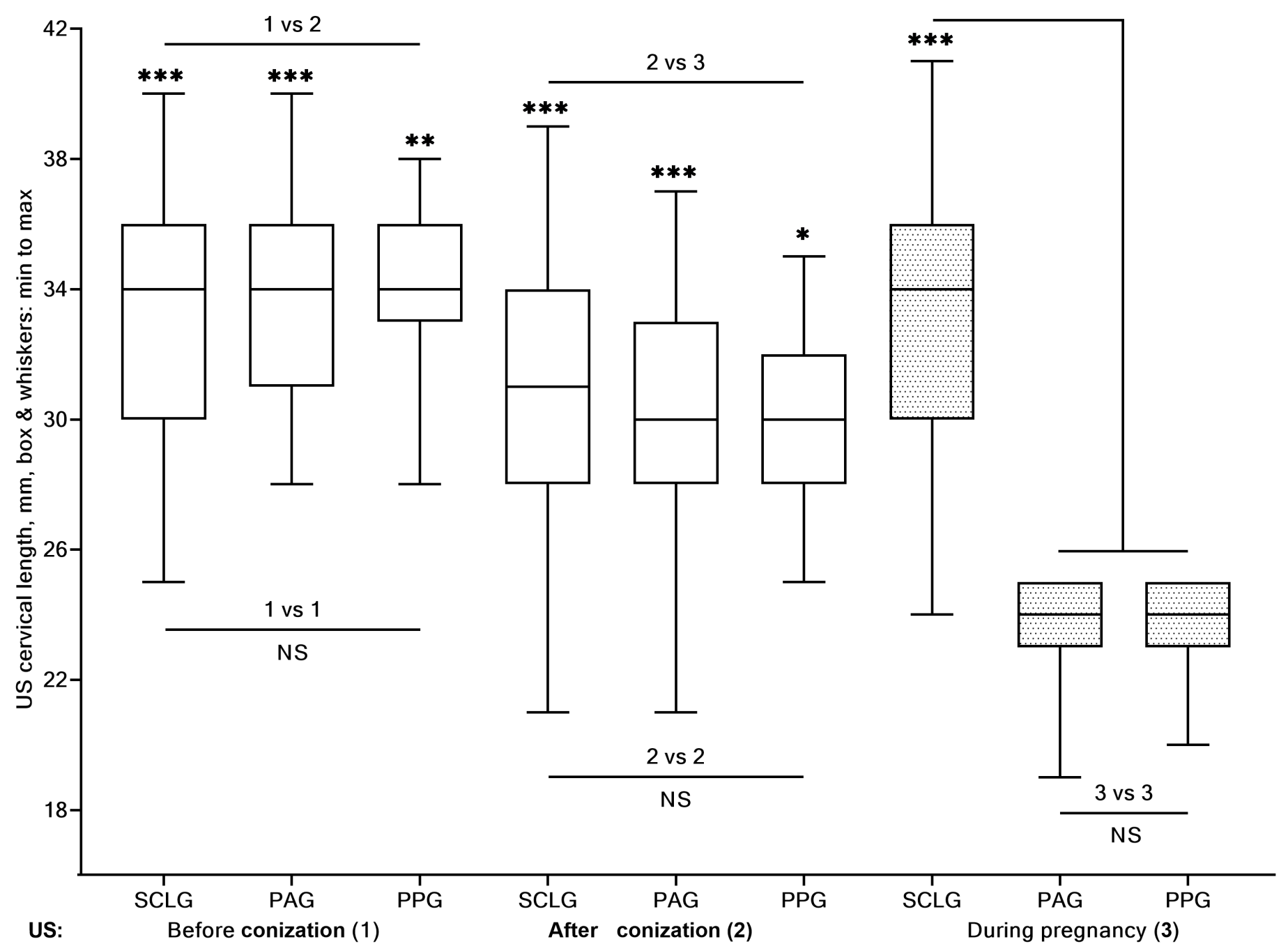

Figure 6

Changes of the ultrasound cervical length (USCL, A) before (1) / after (2) conization and during pregnancy (3) (unit: $\mathrm{mm}$ ) among women with sufficient cervix length group (SCLG), women treated with progesterone alone group (PAG) and progesterone-pessary group (PPG). P-values were achieved by using two-way ANOVA with Tukey's multiple comparisons and Kruskal-Wallis and Dunn's multiple comparisons tests at alpha $=0.05$. 

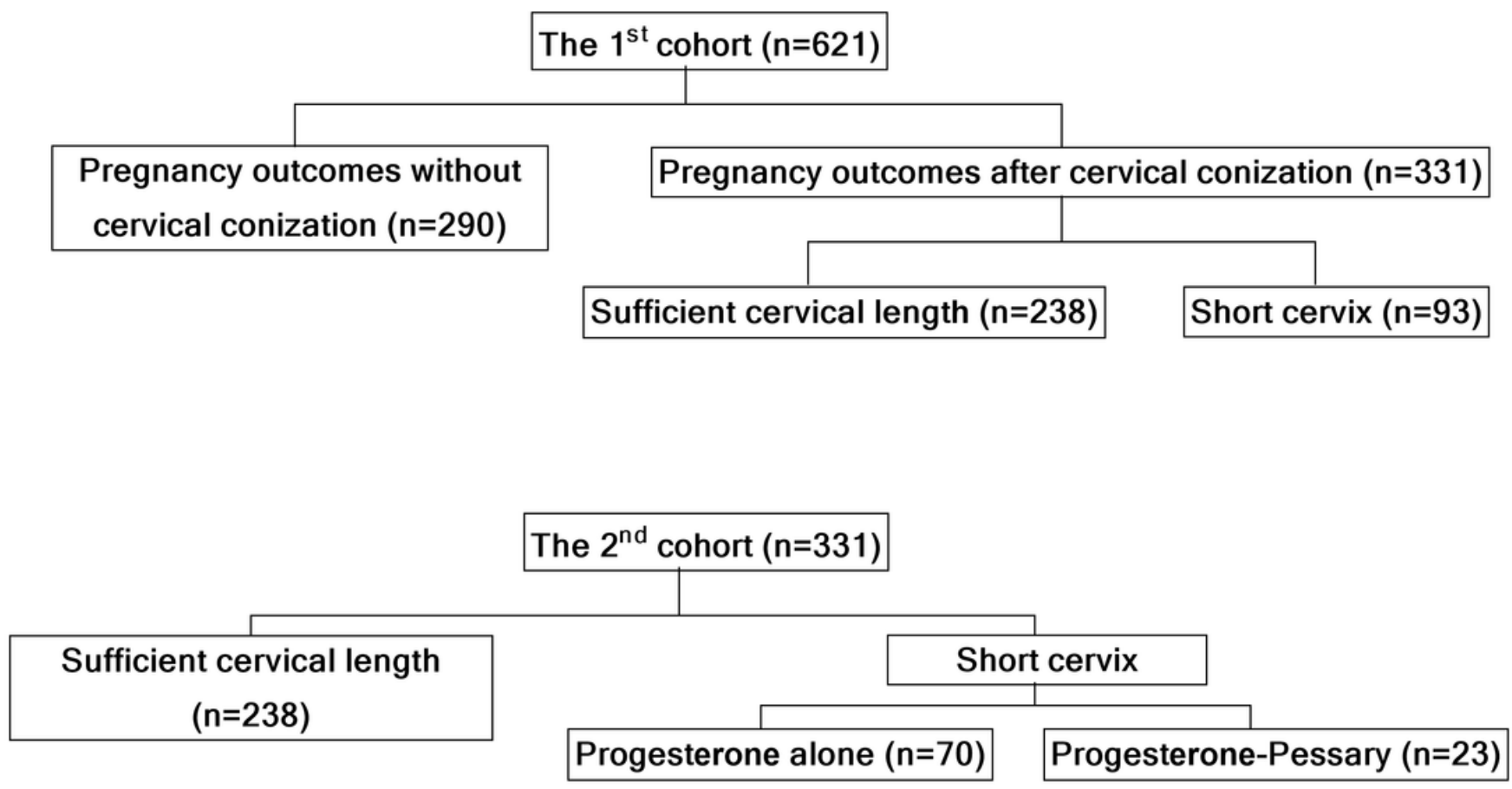

Figure 7

Study design. 

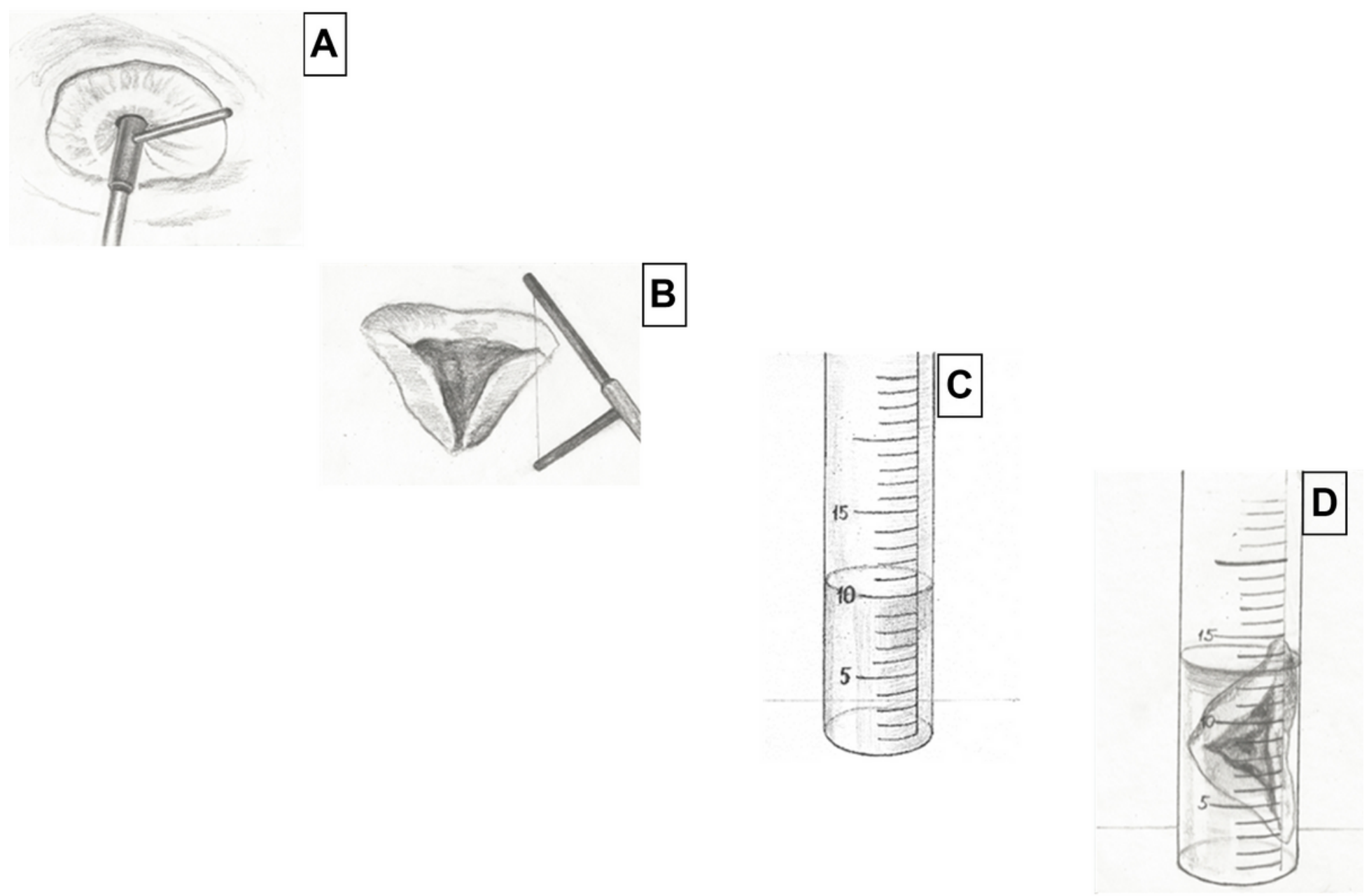

Figure 8

Assessment of the physical cervical conization size (C, unit: $\mathrm{ml}$ ): A - conization of the pathologic part of the cervix; $\mathrm{B}$ - removed sample; $\mathrm{C}$ - a syringe with $10 \mathrm{ml} \mathrm{NaCl}$ isotonic solution; D - estimation of the volume of the removed sample.

\section{Supplementary Files}

This is a list of supplementary files associated with this preprint. Click to download.

- SupplementaryTables.pdf 